\title{
PENGEMBANGAN EDUWISATA DI KAMPUNG WISATA KERANGGAN KOTA TANGERANG SELATAN
}

\author{
Rudy Pramono ${ }^{1}$, Juliana $^{2}$, Emanuel Agung Wicaksono ${ }^{3}$ \\ ${ }^{1,2,3}$ Universitas Pelita Harapan \\ email rudy.pramono@uph.edu, Juliana.stpph@uph.edu
}

\begin{abstract}
Abstrak
Pembentukan Pokdarwis Keranggan merupakan bagian yang tidak terpisahkan dengan Penetapan sebagai Kampung Wisata Keranggan yang berawal dari kemauan dan inisiatif seorang tokoh masyarakat selaku Pembina Home Industri Ibu-Ibu masyarakat Keranggan sebanyak $100 \mathrm{KK}$ di kawasan ekowisata Sungai Cisadane. Difasilitasi oleh beberapa anggota potensi masyarakat bermusyawarah untuk membentuk Kelompok Sadar Wisata. Masyarakat Keranggan menyadari peran dan tanggung jawabnya sebagai Tuan Rumah yang baik bagi Tamu atau wisatawan yang berkunjung untuk mewujudkan lingkungan dan suasana yang kondusif sebagaimana slogan Sapta Pesona. Tujuan kegiatan pengabdian kepada masyarakat ini bertujuan untuk memberikan edukasi mengenai pengetahuan yang berhubungan dengan pariwisata dalam hal kesadaran membuang sampah untuk tidak membuang sampah di sungai dengan pengadaan sarana prasarana eduwisata di Desa Keranggan. Kampung wisata Keranggan membutuhkan kebutuhan sarana dan prasarana ruang belajar terbuka dengan pemanfaatan lahan sebagai sarana edukasi papan informasi teknologi PLTS di destinasi wisata mandiri energi akan menjadi lebih menarik dan tertata di lingkungan ekowisata Keranggan, sehingga pada akhirnya menambah daya tarik wisata. Pengadaan sarana prasarana ini dengan pengelolaan ruang bawah jembatan Cisadane diharapkan dapat bermanfaat sebagai ruang belajar terbuka serta menjadikan kampung wisata Keranggan sebagai produk unggulan dan sebagai destinasi wisata di Kota Tangerang serta terwujudunya pengembangan ekowisata keranggan maupun terwujudnya kawasan yang mendukung kelestarian sumber daya alam dan lingkungan hidup. Saran yang diharapkan adanya peningkatan kualitas SDM sebagai pelaku wisata sebagai destinasi wisata berkembang, serta peningkatan sarana dan prasarana, perbaikan jalan dan air bersih, melakukan pendampingan berkelanjutan dari perguruan tinggi dan menjalankan fungsi pentahelik
\end{abstract}

Kata Kunci : sarana dan prasarana, ruang belajar, kampung wisata, keranggan

\section{PENDAHULUAN}

Pengembangan wisata edukasi merupakan salah satu upaya dalam mewujudkan pariwisata berkelanjutan. Menurut Rohiyatun, Baiq \& Najwa (2021) sarana dan prasarana pendidikan juga menjadi salah satu tolok ukur dari mutu sekolah. Sarana adalah benda bergerak yang dapat digunakan sebagai alat pelaksanaan yang berfungsi sebagai unit kerja, seperti mobil, kuris, meja, komputer, dan lain sebagainya. Prasarana adalah benda tidak bergerak yang dapat menunjang pelaksanaan yang berfungsi sebagai unit kerja, seperti gedung kantor. Sarana dan prasarana adalah salah satu bagian dari komponen yang penting untuk pelaksanaan pendidikan. Maka kebutuhan sarana dan prasarana harus dipenuhi. Upaya memenuhi sarana dan prasarana adalah dengan manajemen sarana dan prasarana.(Dewi, 2020). Salah satu faktor penghambat manajemen sarana dan prasarana Pendidikan 842 
adalah kurangnya dana serta penempatan fasilitas harus lebih fokus agar pengguna fasilitas merasakan kenyamanan.(Sinta, 2019). Menurut fungsi manajemen sarana dan prasarana sekolah alam, perencanaan, pengadaan, inventarisasi, pemeliharaan, penggunaan sarana dan prasarana serta keefektifan penggunaan sarana dan prasarana sekolah alam (Hakim, 2016).

Wisata pendidikan atau edutourism adalah sektor ekonomi yang berkembang pesat dan semakin populer saat ini. Edutourism adalah kegiatan wisata dari wisatawan yang melakukan liburan semalam dan yang melakukan perjalanan wisata, di mana pendidikan dan pembelajaran merupakan bagian utama atau sekunder dari perjalanannya. Peningkatan mobilitas pendidikan sangat mengesankan dan bukan hanya perjalanan, ini adalah perubahan unik bagi anak-anak dan remaja untuk menikmati alam dan alam bebas dan aktif secara fisik, terlibat dalam olahraga.(Yfantidou \& Goulimaris, 2018). Selain itu, edutourism juga dapat mempromosikan keberlanjutan dan mengubah wisatawan muda menjadi konsumen dan pelancong masa depan yang bertanggung jawab, yang menghormati dan melindungi alam.Edutourism sangat mempengaruhi universitas, pelancong, agen perjalanan, perusahaan asuransi, dan banyak lainnya, namun ada sedikit studi yang memahami tren penelitian edutourism.(Kamdi et al., 2016). Wisata budaya/Edutourism, dilihat sebagai formula pendidikan non formal seumur hidup yang dipimpin oleh individu, juga memainkan peran penting, meningkatkan nilai dalam arti yang lebih luas (Costa et al., 2017). Memantau opini masyarakat tentang kota dan mengajak mereka untuk berpartisipasi aktif juga mencerahkan gerakan tersebut.Wisata edukasi atau edu-tourism adalah sektor ekonomi yang berkembang pesat dan semakin populer saat ini. Menurut akademisi, Konsep wisata edukasi memiliki cakupan yang luas dan terus berkembang berubah sebagai konsep pariwisata itu sendiri (Akhmedova, 2016). Dalam bidang pendidikan dan pariwisata, kita mengenal istilah edutourism dapat menjadi solusi dalam memanfaatkan potensi lokal pariwisata sebagai sumber belajar (Hayati, 2017). Ekowisata dikenal sebagai pariwisata berkelanjutan, pariwisata hijau, dan eduwisata karena memiliki visi kelestarian lingkungan, kegiatan tanpa polusi, konservasi, pemberdayaan masyarakat, dan penghargaan terhadap alam dan budaya masyarakat (Maryani \& Yani, 2016) Tetapi fakta di lapangan banyak ditemukan sarana dan prasarana yang tidak dioptimalkan dan dikelola dengan baik. Berangkat dari potensi alam dan budaya yang ada di kampung Keranggan, dilintasi oleh sungai Cisadane yang berada di sebelah barat yang masih alami, hijau, sejuk dan asri merupakan suatu kekayaan alam yang dapat dimanfaatkan untuk dijadikan ekowisata. Keberhasilan Kampung Wisata Keranggan adalah merupakan partisipasi dari masyarakat dan langsung akan dirasakan oleh masyarakat. Potensi alam dan budaya yang ada di kampung Keranggan sangat perlu dilestarikan dan dikembangkan.

Dengan pengelolaan yang terpadu, Kampung Wisata Keranggan berpotensi untuk menggerakkan ekonomi daerah, melestarikan lingkungan dan mensejahterakan masyarakat disekitar kawasan yang dikembangkan sebagai pariwisata alam (Ekowisata) Keranggan numbering,

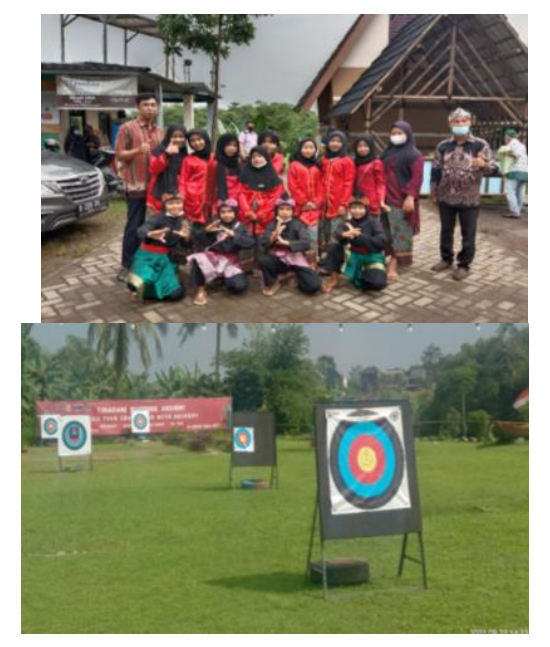

Gambar 1. Desa Wisata Keranggan

Terdapat berbagai industri skala mikro dan kecil yang menjadikan kampung Keranggan sebagai sentra industri rumah tangga produk makanan dan kerajinan yang cukup terkenal di Tangerang Selatan dan sekitarnya. Diantara jenis makanan yang cukup populer dari Keranggan adalah kacang sangrai yang proses menggorengnya menggunakan pasir dan tanpa minyak goreng, serta rengginang, aneka keripik singkong, keripik pisang, opak, enyek dan lain - lain. Banyak pengunjung dari berbagai daerah melakukan kajian dan kunjungan untuk melihat secara langsung dan mencoba sendiri proses 
memasaknya. Demikian juga proses pembuatan keset, sablon kaos atau barang kerajinan lainnya.

Keadaan alam yang masih alami dengan mata pencaharian penduduk sebagian besar pelaku home industri makanan dan petani, mudah dijangkau oleh para pengunjung dari berbagai daerah.

Konsep Ekowisata Keranggan dalam pengelolaan obyek wisata yang sekaligus memiliki fungsi ekonomis bagi penduduk setempat dan masyarakat sekitarnya serta fungsi konservasi dan pendidikan untuk sumberdaya yang ada di dalamnya (Kristiana \& Pramono, 2018)

Keranggan yang berbudaya Sunda, kini melalui ekowisata Keranggan sedang dikembangkan Therapy Gerak Kesehatan "YAMA" untuk meningkatkan imun tubuh dengan degung khas sunda dan pembinaan kepada generasi muda untuk pelestarian seni dan budaya. Permasalahan yang terdapat dalam kampung wisata keranggan meliputi Belum tertatanya kondisi kawasan Kampung Wisata Keranggan mengingat belum optimal fasilitas-fasilitas pariwisata. Masih kurangnya kesadaran pelaku wisata dan masyarakat akan pentingnya kebersihan di lokasi. Sumber Daya Masyarakat yang harus terus di edukasi tentang: pengetahuan yang berhubungan dengan pariwisata, kesadaran dalam membuang sampah untuk tidak membuang sampah di sungai Masih kurangnya fasilitas-fasilitas pendukung wisata

\section{METODE}

Kampung Keranggan terletak di Kota Tangerang Selatan secara geografis dilintasi oleh sungai Cisadane yang berada di sebelah barat, tepatnya di Kelurahan Keranggan Kecamatan Setu, dikelilingi dengan perumahan mewah dan tidak jauh dari pusat kota mandiri Bumi Serpong Damai. Kondisi alam tanahnya yang berkontur dan naik turun menjadi daya tarik alam tersendiri. Kelurahan Keranggan memiliki Luas wilayah : 1,70 KM2 dimana didalamnya Kampung Wisata Keranggan terdiri dari $280 \mathrm{KK}$ hampir $40 \%$ dari penduduknya pelaku Home industry. Keranggan yang berbatasan dengan : Sebelah barat : sungai cisadane bersebrangan dengan Cisauk Tangerang. Sebelah utara : Kademangan

Sebelah selatan : Puspitek, Buaran, Gunung Sindur
Jarak dari Pusat Pemerintahan Kecamatan : $3 \mathrm{~km}$ Jarak dari Pemerintahan Kota : $9 \mathrm{~km}$. Jarak dari Ibukota Propinsi : $60 \mathrm{~km}$. Masyarakat Keranggan memiliki makanan khas berupa kacang dan aneka keripik yang diproduksi dan dikelola oleh masyarakat petani lokal. Suasana kampung Keranggan yang masih tetap asri di beberapa bagian wilayah tertentu dengan kekhas-an nya menjaga keasrian sungai cisadane yang membentang lebar dan jernih pada musim kemarau menambah keasriannya. (Pramono, 2019) Pelaksanaan pengabdian kepada masyarakat dilakukan secara luring dengan peserta 11 orang.

\section{HASIL DAN PEMBAHASAN}

Kegiatan direncanakan sejak bulan Juli dengan melakukan wawancara dengan mitra untuk mengetahui permasalahan dan kebutuhan dari mitra. Kegiatan pengadaan sarana dan prasarana dilakukan secara langsung ke kampung wisata keranggan dan dilakukan pembagian kuesioner secara online melalui google form dengan hasil sebagai berikut .

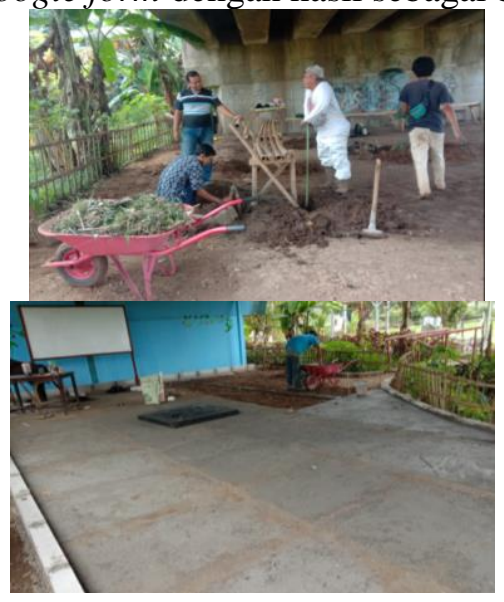

Gambar 2 Pembangunan Sarana Belajar Eduwisata 


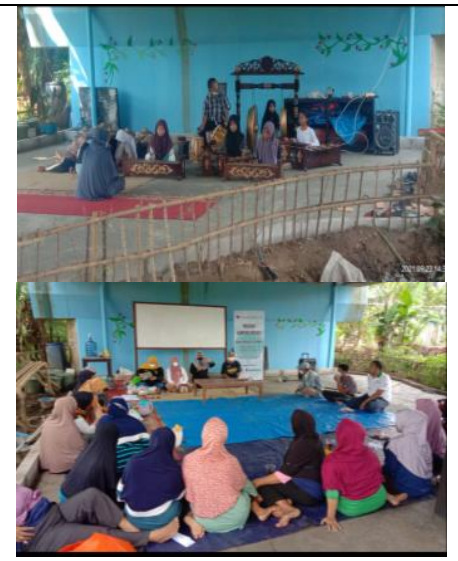

Gambar 3 Pemanfaatan Sarana Eduwisata

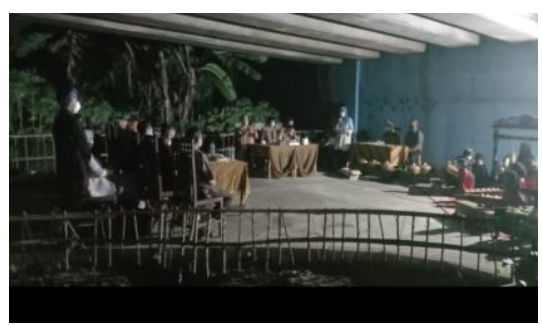

Gambar 4 Penilaian Lomba Desa Wisata oleh Dinas Pariwisata Prov. Banten.

Hasil kuesioner peserta kegiatan, terdapat 4 orang (36.4\%) menyatakan sangat setuju, 3 orang $(27.3 \%)$ agak setuju dan 4 orang $(36.4 \%)$ cukup setuju bahwa materi terorganisasi dengan baik dan mudah dimengerti. Terdapat 4 orang (36.4\%) menyatakan sangat setuju, 5 orang $(45.5 \%)$ menyatakan agak setuju, 2 orang (18.2\%) menyatakan cukup setuju bahwa materi sangat relecan dan telah sesuai dengan yang diharapkan Terdapat 6 orang $(54.5 \%)$ menyatakan sangat setuju, 3 orang (27.3\%) menyatakan agak setuju, 2 orang $(18.2 \%)$ menyatakan cukup setuju dalam memahami cara pengelolaan sarana dan prasarana yang baik agar menjadi daya tarik wisata, Terdapat 7 orang $(63.6 \%)$ menyatakan sangat setuju, 2 orang (18.2\%) menyatakan cukup setuju, 2 orang (18.2\%) menyatakan agak setuju bahwa perlunya pengadaan kebutuhan seragam di desa wisata Keranggan.

Tabel 1. Tersedianya sarana dan prasarana

\begin{tabular}{|l|l|l|c|}
\hline Item & Pernyataan & Total & $\begin{array}{c}\text { Persentase } \\
(\%)\end{array}$ \\
\hline $\begin{array}{l}\text { Infrastruktur Jalan } \\
\text { Masuk }\end{array}$ & Sangat baik & 2 & 18.2 \\
\cline { 2 - 4 } & Cukup baik & 4 & 36.4 \\
\cline { 2 - 4 } & Agak baik & 4 & 36.4 \\
\cline { 2 - 4 } & Agak tidak & 1 & 9.1 \\
\hline
\end{tabular}

\begin{tabular}{|c|c|c|c|}
\hline & baik & & \\
\hline \multirow{3}{*}{$\begin{array}{l}\text { Ketersediaan sarana } \\
\text { transportasi }\end{array}$} & Sangat baik & 1 & 9.1 \\
\hline & Cukup baik & 5 & 45.5 \\
\hline & Agak Baik & 5 & 45.5 \\
\hline \multirow{3}{*}{$\begin{array}{l}\text { Rambu-rambu } \\
\text { penunjuk jalan }\end{array}$} & Sangat baik & 1 & 9.1 \\
\hline & Cukup baik & 3 & 27.3 \\
\hline & Agak Baik & 7 & 63.6 \\
\hline \multirow{4}{*}{$\begin{array}{l}\text { Keberadaan sarana } \\
\text { dan prasarana }\end{array}$} & Sangat baik & 1 & 9,1 \\
\hline & Cukup baik & 2 & 18.2 \\
\hline & Agak Baik & 7 & 63.6 \\
\hline & baik & 1 & 9.1 \\
\hline \multirow{4}{*}{$\begin{array}{l}\text { Kondisi sarana dan } \\
\text { prasarana }\end{array}$} & Sangat baik & 1 & 9.1 \\
\hline & Cukup baik & 1 & 9.1 \\
\hline & Agak Baik & 8 & 72.7 \\
\hline & $\begin{array}{ll}\begin{array}{l}\text { Agak } \\
\text { baik }\end{array} & \text { tidak } \\
\end{array}$ & 1 & 9.1 \\
\hline \multirow{3}{*}{$\begin{array}{l}\text { Tersedia Sarana } \\
\text { Prasarana Warung }\end{array}$} & Sangat baik & 6 & 36.4 \\
\hline & Cukup baik & 6 & 54.5 \\
\hline & baik & 1 & 9.1 \\
\hline \multirow{3}{*}{$\begin{array}{l}\text { Pemanfaatan sarana } \\
\text { dan prasarana }\end{array}$} & Sangat baik & 2 & 18.2 \\
\hline & Cukup baik & 4 & 36.4 \\
\hline & Agak baik & 5 & 45.5 \\
\hline \multirow{3}{*}{$\begin{array}{ll}\begin{array}{l}\text { Tersedia } \\
\text { informasi }\end{array} & \text { Pusat } \\
\end{array}$} & Sangat baik & 1 & 9.1 \\
\hline & Cukup baik & 4 & 36.4 \\
\hline & Agak baik & 6 & 54.5 \\
\hline \multirow[t]{3}{*}{ Tersedia Parkir } & Sangat baik & 2 & 18.2 \\
\hline & Cukup baik & 2 & 18.2 \\
\hline & Agak baik & 7 & 63.6 \\
\hline \multirow{4}{*}{$\begin{array}{ll}\text { Tersedia } & \text { Tempat } \\
\text { Sampah } & \end{array}$} & Sangat baik & 1 & 9.1 \\
\hline & Cukup baik & 3 & 27.3 \\
\hline & Agak baik & 6 & 54.5 \\
\hline & $\begin{array}{ll}\text { Agak } & \text { tidak } \\
\text { baik } & \\
\end{array}$ & 1 & 9.1 \\
\hline \multirow[t]{5}{*}{ Tersedia pondok } & Sangat baik & 1 & 9.1 \\
\hline & Cukup baik & 1 & 9.1 \\
\hline & Agak baik & 5 & 45.5 \\
\hline & baik & 3 & 27.3 \\
\hline & $\begin{array}{l}\text { Agak tidak } \\
\text { baik }\end{array}$ & 1 & 9.1 \\
\hline \multirow[t]{4}{*}{ Tersedia Toilet } & Sangat baik & 1 & 9.1 \\
\hline & Cukup baik & 4 & 36.4 \\
\hline & Agak baik & 5 & 45.5 \\
\hline & baik & 1 & 9.1 \\
\hline \multirow[t]{3}{*}{ Tersedia Musholla } & Sangat baik & 3 & 27.3 \\
\hline & Cukup baik & 2 & 18.2 \\
\hline & Agak baik & 6 & 54.5 \\
\hline \multirow{5}{*}{$\begin{array}{l}\text { Jalan } \\
\text { Setapak/Jembatan }\end{array}$} & Sangat baik & 1 & 9.1 \\
\hline & Cukup baik & 3 & 27.3 \\
\hline & Agak baik & 4 & 36.4 \\
\hline & baik & 1 & 9.1 \\
\hline & $\begin{array}{ll}\text { Agak } & \text { tidak } \\
\text { Baik } & \\
\end{array}$ & 2 & 18.2 \\
\hline \multirow[t]{4}{*}{ Kebersihan } & Sangat baik & 1 & 9.1 \\
\hline & Cukup baik & 2 & 18.2 \\
\hline & Agak baik & 6 & 54.5 \\
\hline & baik & 2 & 18.2 \\
\hline \multirow{2}{*}{$\begin{array}{ll}\text { Kepuasan } & \text { dalam } \\
\text { pengguna } & \text { sarana }\end{array}$} & Sangat baik & 1 & 9.1 \\
\hline & Cukup baik & 2 & 18.2 \\
\hline
\end{tabular}




\begin{tabular}{|l|l|l|c|}
\hline dan prasarana & Agak baik & 7 & 63.6 \\
\cline { 2 - 4 } & baik & 1 & 9.1 \\
\hline \multirow{4}{*}{ Jaringan } & Cukup baik & 2 & 18.2 \\
\cline { 2 - 4 } & Agak baik & 7 & 63.6 \\
\cline { 2 - 4 } & $\begin{array}{l}\text { Agak tidak } \\
\text { baik }\end{array}$ & 2 & 18.2 \\
\hline Jaringan Listrik & Sangat baik & 2 & 18.2 \\
\cline { 2 - 4 } & Cukup baik & 2 & 18.2 \\
\cline { 2 - 4 } & Agak baik & 6 & 54.5 \\
\cline { 2 - 4 } & $\begin{array}{l}\text { Agak Tidak } \\
\text { baik }\end{array}$ & 1 & 9.1 \\
\hline Instalasi air bersih & Sangat baik & 1 & 9.1 \\
\cline { 2 - 4 } & Cukup baik & 5 & 45.5 \\
\cline { 2 - 4 } & $\begin{array}{l}\text { Agak Tidak } \\
\text { baik }\end{array}$ & 5 & 45.5 \\
\hline \multirow{3}{*}{$\begin{array}{l}\text { Sistem pembuangan } \\
\text { limbah }\end{array}$} & Sangat baik & 1 & 9.1 \\
\cline { 2 - 4 } & Cukup baik & 6 & 54.5 \\
\cline { 2 - 4 } & $\begin{array}{l}\text { Agak Tidak } \\
\text { baik }\end{array}$ & 4 & 36.4 \\
\hline
\end{tabular}

Sumber : Hasil olahan data (2021)

\section{KESIMPULAN}

Hasil kegiatan pengabdian kepada masyarakat diharapkan adanya peningkatan sarana dan prasarana secara berkelanjutan serta peningkatan sumber daya manusia sebagai destinasi wisata, pelatihan sadar wisata, pendampingan dari perguruan tinggi dan menjalankan fungsi pentahelik, serta adanya peran serta masyarakat dalam menjaga stabilitas dan kemajuan desa wisata ke depannya.

\section{REFERENSI}

Akhmedova, O. O. (2016). Educational tourism: Defining the concept Repository Simon Kuznets Kharkiv National University of Economics Retrieved September (Kristiana \& Pramono, 2018)27, 2021 from http://www.repository.hneu.edu.ua/jspui/bitstr eam/123456789/12394/1/\%D1\%82\%D0\%B5 $\% D 0 \% B 7 \% D 0 \% B 8 \_\% D 0 \% 9 D \% D 0 \% A 3 \% D 0$ $\% A 6 \% D$.

Costa, I., Joukes, V., Diniz, F., \& Cantante, A. C. (2017). Cities and enhancement of their historic centre and heritage: Educational communities' and visitors' perspectives. Regional Science Inquiry, 9(1), 85-95. https://www.scopus.com/inward/record.uri?eid $=2$-s 2.0 -

$85026314057 \&$ partnerID=40\&md5=f656a239 
$1-5$.

Sinta, M. I. (2019). Manajemen Sarana dan Prasarana. Jurnal Isema Islamic Educational Management, 4(1), 77-92. https://doi.org/10.15575/isema.v3i2.5645

Yfantidou, G., \& Goulimaris, D. (2018). The exploitation of edutourism in educational society: A learning experience necessity through physical activity and recreation . Sport Science, $\quad 11(1), \quad 8-15$. https://www.scopus.com/inward/record.uri?eid $=2-\mathrm{s} 2.0-$

$85055318599 \&$ partnerID $=40 \&$ md5=ab74e9bf 53b6b9a7cbbbbcd65fb158df 